Claremont Colleges

Scholarship@ Claremont

All HMC Faculty Publications and Research

HMC Faculty Scholarship

$1-1-2005$

\title{
Digital Harmony of Sound and Light
}

Bill Alves

Harvey Mudd College

\section{Recommended Citation}

Bill Alves. Digital Harmony of Sound and Light. Computer Music Journal, 29:4, pp. 45-54, Winter 2005 doi: 10.1162/ 014892605775179982

This Article is brought to you for free and open access by the HMC Faculty Scholarship at Scholarship @ Claremont. It has been accepted for inclusion in All HMC Faculty Publications and Research by an authorized administrator of Scholarship @ Claremont. For more information, please contact scholarship@cuc.claremont.edu. 


\section{Bill Alves}

Harvey Mudd College

301 E. 12th St.

Claremont, California 91711

alves@hmc.edu

\section{Digital Harmony of Sound and Light}

The sounds and compositional resources available in Just intonation first attracted me as a composer.

Though the Pythagorean tradition receded with the adoption of musical temperament and other compositional structures for visual arts and architecture, Sir Isaac Newton and others proposed a connection of sound and vision through the wave properties of color in light and pitch in music (Jones 1972). Arguably the first efforts to use technology to apply concepts of musical composition to abstract arts of motion came with a series of experimental devices from the 18th through the 20th centuries generally called "color organs." Most famously, the composer Aleksandr Skryabin's Prométhée includes a part for such an instrument which would project the colors of Skryabin's synesthetic associations. However, the technology these innovators used allowed only poor and vague definition of visual form (Collopy 2000).

The technology of filmed animation offered much greater control over form and direct synchronization to music. The great abstract animator Oskar Fischinger created a remarkable series of films in the first half of the twentieth century in which he represented the sounds of accompanying music often with delicately fluid forms (Moritz 2004). Many of his films are a kind of supple choreography distilled to abstraction, but relying on an intuitive sense of connection to musical form.

\section{Mapping Vision to Sound}

Distinct approaches to the correspondences between sound and light are at least as important as differences in technique in distinguishing the work of artists in this tradition. Many artists, from the 18th-century inventor of a "color harpsichord," Louis-Bertrand Castel, to modern creators of music visualizer software, have attempted to directly illustrate music, mapping pitch to spatial height or color hue, for example (Klein 1937). The Music Animation Machine (www.musanim.com/) of Stephen Malinowski is especially interesting in this approach. 
However, though artists often speak of "color harmony," attempts to create a direct mapping of color relationships to the immediacy of musical consonance and dissonance have largely failed.

To Whitney, such a direct, synesthetic mapping of music's most basic parameters (pitch, loudness, and so forth) failed to capture the expressive vision of great works of music, which, to him, depended more directly on multidimensional interplay of tension and resolution. Moreover, he advocated an approach in which animation, instead of being a direct representation of music, corresponds to this higher level of aesthetic intention, creating what he termed "complementarity" (Whitney 1984).

\section{Whitney's Differential Dynamics}

John Whitney recognized that digital computers could uniquely and directly realize in animated form the same kind of harmonic movement found in music in ways never imagined by the Greeks. Beginning in the 1960s, Whitney created a series of extraordinary films of abstract animation that used computers to create a harmony not of color, space, or musical intervals, but of motion.

In his 1980 book Digital Harmony: On the Complementarity of Music and Visual Art, Whitney hypothesized that Pythagorean harmony could be matched in visual art: "This hypothesis assumes the existence of a new foundation for a new art. It assumes a broader context in which Pythagorean laws of harmony operate. . . In other words, the hypothesis assumes that the attractive and repulsive forces of harmony's consonant/dissonant patterns function outside the dominion of music" (p. 5). More particularly, Whitney discovered that if he set a large number of elements into repetitive motion such that the motion of the second was two times the speed of the first, the third three times the speed of the first, and so on, the animation that would result would demonstrate beautiful patterns of symmetry at points corresponding to the same ratios that define musical consonances.

(Tenney [1988] reminds us that the terms consonance and dissonance have been used in many dif- ferent senses throughout history. In particular, we must be careful to distinguish between consonance as a psychoacoustical phenomenon, which may depend in large part on the closeness of the frequency proportions to ratios of relatively small whole numbers, my focus here, and consonance in a more general sense as harmonic stasis or resolution, which may be created in many different ways.)

Though Whitney's films brilliantly demonstrate how computer animation can effectively create a temporal sensation of attraction and repulsion, of tension and resolution, he was never able to take the next step of creating music to correspond directly to those visual images.

To take a very simple example of what Whitney called "differential dynamics," imagine a set of points going around a circle, the second traveling twice the speed of the first, the third three times the speed of the first, and so on, all starting together at the twelve o'clock position. By the time the slowest point reaches halfway around the circle, all the points will align with either the six or twelve o'clock position. If the slowest point is at either the one-third or two-thirds position, all points will line up at the thirds: twelve, four, or eight o'clock. When the slowest point is at a position around the circle which is not a very clear integer divisor of the circle's perimeter, the points will appear scattered somewhat randomly, and the eye will not detect a clear pattern.

\section{Whitney's Works}

Of course points moving around a circle is a very simple example. In his films Matrix I and III (1970 and 1972), Whitney had points or other shapes move around parametric curves. In Permutations (1968), the points move in various rose curves (sine functions in polar coordinates), and in Arabesque (1973) points initially arranged in a circle move linearly but wrap around at the edge of the screen (see Figure 1). In all of these examples, the same points of resonance, of striking symmetry, occur at the same points of harmonic proportions.

Each of these early films, created by photographing frames from a CRT monitor with an animation 
Figure 1. Images from John Whitney's 1973 film

Arabesque. Images reproduced with the permission of the Estate of John and James Whitney.

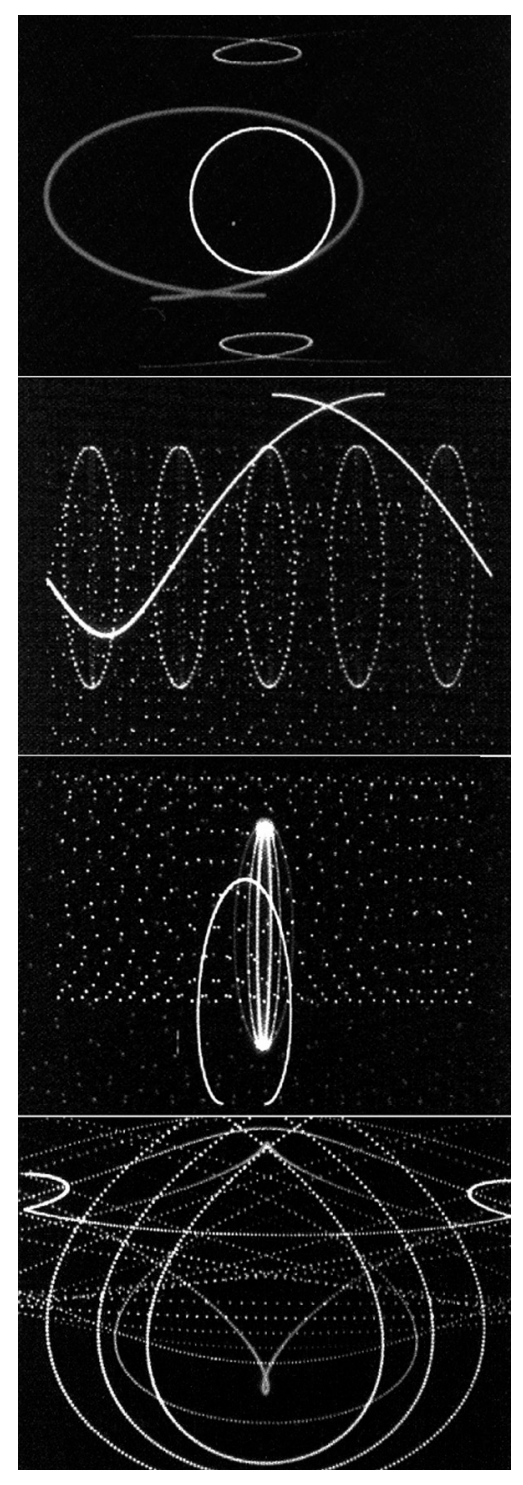

camera and then combining them and adding color with an optical printer, is an intricate composition arranged in sections in which various themes are developed. Most distinctively, these films create form through the manipulation of expectation, resolution, and surprise, mostly achieved through the technique of differential dynamics. However, with the exception of Matrix I, Whitney avoided soundtracks with conventional tonal harmonic progres- sions, whose sequences of harmonic tension and resolution might conflict with those he was presenting visually.

An effort to move to an interactive compositional system led him to create works of very low color and spatial resolution on an IBM PC in the 1980s. Although not nearly as immediately attractive as his earlier works, these pieces, collected as Moon Drum (1991), allowed him to develop works of compositional complexity and nuance. With this software, developed by Jerry Reed, he was also able to send out MIDI messages at keyframes, creating his own soundtrack of non-metrical FM tones and drum machine crashes. Whereas this approach allowed for musical articulation of important points of the animation, it hardly demonstrated the possibilities of a true complementarity, to use Whitney's term, of visual and musical composition.

\section{Differential Dynamics in Music}

In the composing software that Whitney and I planned, he envisioned multitudes of sine waves rising and falling in correspondence to the spatial motion of the elements on the screen. However, I soon realized that a literal mapping of pitch space to height on the screen was only intuitive because our culture has adopted that particular arbitrary metaphor of "low" and "high" to describe pitch. Though other pioneers of connections between music and the visual arts have explored such a mapping, it does not retain the possibility of musical consonance resulting in visually "consonant" patterns.

The fact that whole number proportions create these arresting patterns of visual resonance suggest a correspondence, or complementarity, to consonant musical sonorities created by whole number frequency ratios, that is, Just intonation. Seeing that Just musical intervals occur naturally in the harmonic series, many Just intonation composers, such as La Monte Young, have focused on the compositional resources of frequency ratios related implicitly to a common fundamental, a relationship Partch (1974) terms an otonality.

However, the proportions of Whitney's differential 
dynamics suggest a different kind of relationship. In the example of points moving around a circle, when the first point reaches the one-third point in the circle, all the points are aligned to the 12:00, 4:00, and 8:00 positions. By treating the 12:00 position as the fundamental, the one-third point would represent a $3 / 1$ frequency ratio and the two-thirds point the $3 / 2$ frequency ratio. (Just intonation ratios are conventionally notated with the larger number in the numerator. I have adopted this convention for ratios of both frequencies and visual proportions, as in this example.)

Similar patterns would occur at other wholenumber divisions, but with increasing complexity as that whole number increases. Thus a five-fold division of the circle would correspond to frequency ratios of $5 / 5$ (that is, $1 / 1$, the fundamental), $5 / 4,5 / 3$, $5 / 2$, and $5 / 1$. Unlike the harmonic series, this set of musical intervals has a constant factor in the numerator. This set defines what Partch called an utonality and what others have called a subharmonic series (that is, the inversion of the harmonic series). Subharmonic series occur with combinations of any integer divisions of a whole, as with divisions of string lengths or evenly spaced holes on aerophones, for example.

The higher the numerator, or number of divisions, what Partch calls the numerary nexus, the further along the spectrum we are towards dissonance. The smaller this common factor or numerary nexus, the more stable but less dynamic the sound and image. Thus the frequency ratio of $2: 1$ is the octave, which, as with the differential dynamics example, results in a profoundly stable but not very interesting consonance. Somewhat more complex factors such as 5 or 7 , which offer more interesting musical consonances, result in fascinating symmetrical patterns that catch the eye's attention when applied the differential dynamics system.

Figure 2 demonstrates examples of these points of consonance, first in the simple example of points moving in a circle, then in a more complex rosecurve pattern, and finally as a set of tones in the same proportions. The number in the first column represents the proportion that the slowest element has traversed through the entire cycle, and hence the common factor or numerary nexus of all the ele- ments. At points where this number represents a ratio of relatively small whole numbers, symmetrical patterns emerge.

The right-hand column of Figure 2 shows the chords that would result if a set of sixteen pitches went through the same differential cycle. The beginning position (12:00 in circular motion), the fundamental, is here set to $\mathrm{C} 2$. One quarter through the cycle, for example, would represent a 4/1 ratio, or a frequency four times $\mathrm{C} 2$. To represent some of the pitches poorly approximated by twelve-tone notation, I have used an accidental of an arrow up or down to represent a pitch inflection of about 33 cents and a plus sign to indicate raising the pitch about 15 cents. The final row is an example of how both visual and aural dissonance results when the common factor is irrational or sufficiently complex.

Artists such as Ronald Pellegrino have discovered similar points of correspondence between Just intonation and visual symmetry through the use of analog electronics, especially the oscilloscope (Pellegrino 1983). When two tones of relatively simple whole number frequency relationships are connected to the $x$ and $y$ inputs of an oscilloscope (or the vibrating mirrors of a laser scanner), the resulting visual form will be a Lissajou figure of relative stability and symmetry. The algorithms of Monro and Pressing (1998) demonstrate similar relationships between Just intonation harmonies and visual symmetries in more extensible and elaborate ways. However, Whitney intended differential dynamics to provide a set of principles which could be applied compositionally in many different forms, rather than algorithms for visualization.

\section{New Explorations}

In my first video based on these principles, Hiway 70 (1997), I extended the polar coordinate curves of Whitney's Permutations to three-dimensional graphics. But the most important way in which my work was distinguished from his is that, approaching this work as a composer, I created a soundtrack in tandem with the visual composition, carefully synchronizing movement between points of tension and dissonance and points of stability and tonal 
Figure 2. Correspondences between points of visual resonance in two examples of differential motion and musical pitches (see text).

\section{Differential dynamics}

Common example-spheres moving

factor

1
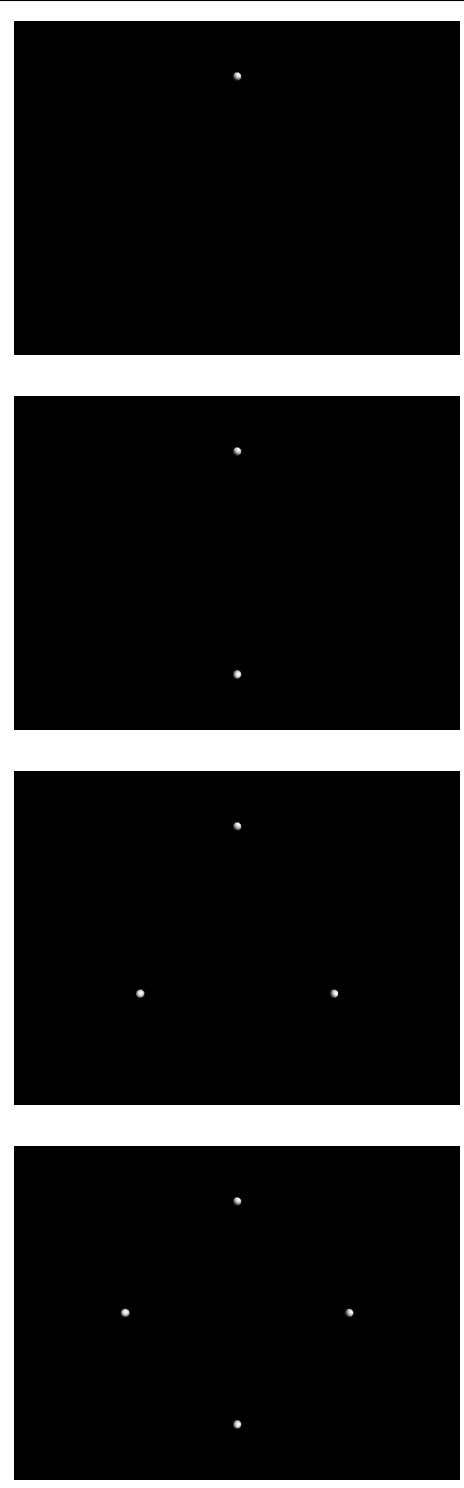

5
Differential dynamics example-spheres moving in a rose curve pattern
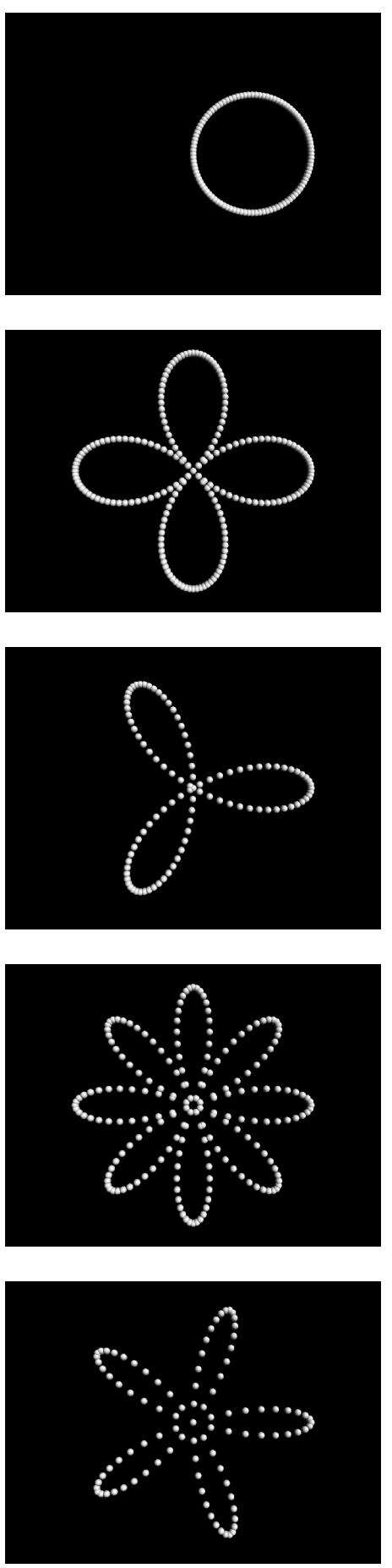
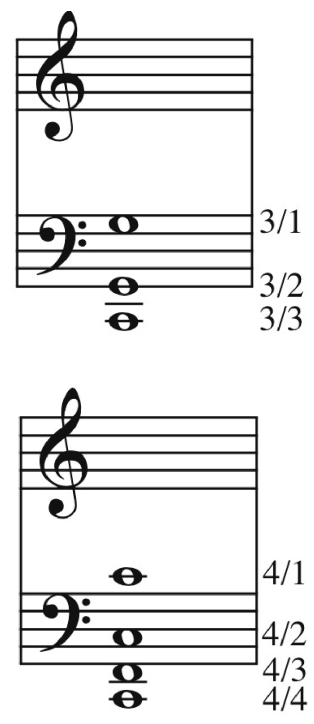

Musical correspondence pitches are approximate
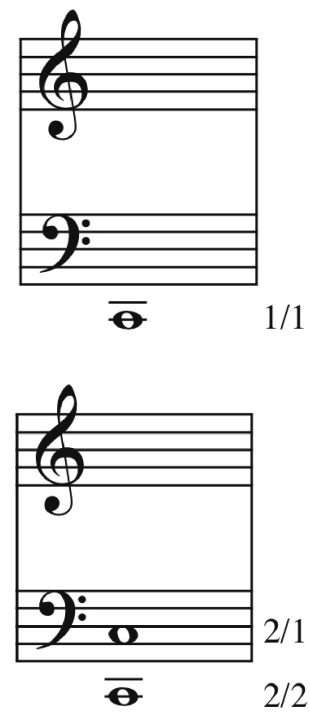

$2 / 2$

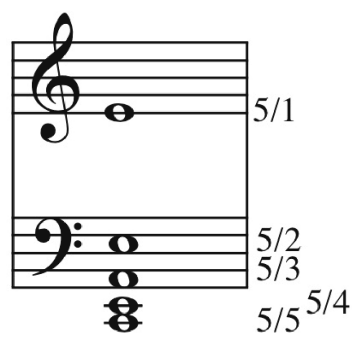


Differential dynamics

Common example-spheres moving

factor

6 in a circle
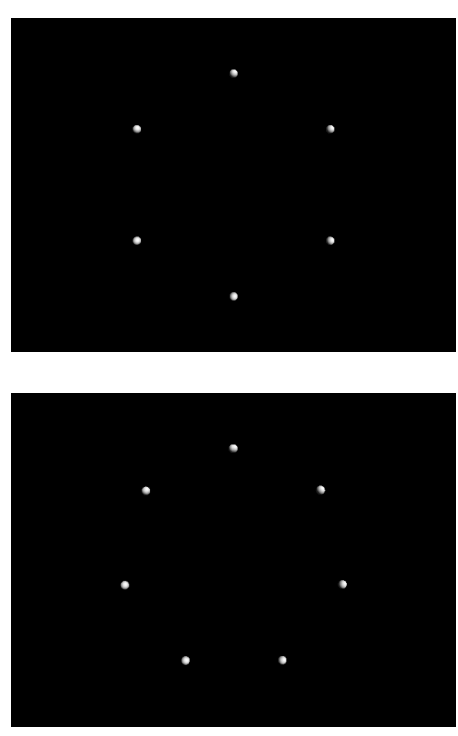

8

9
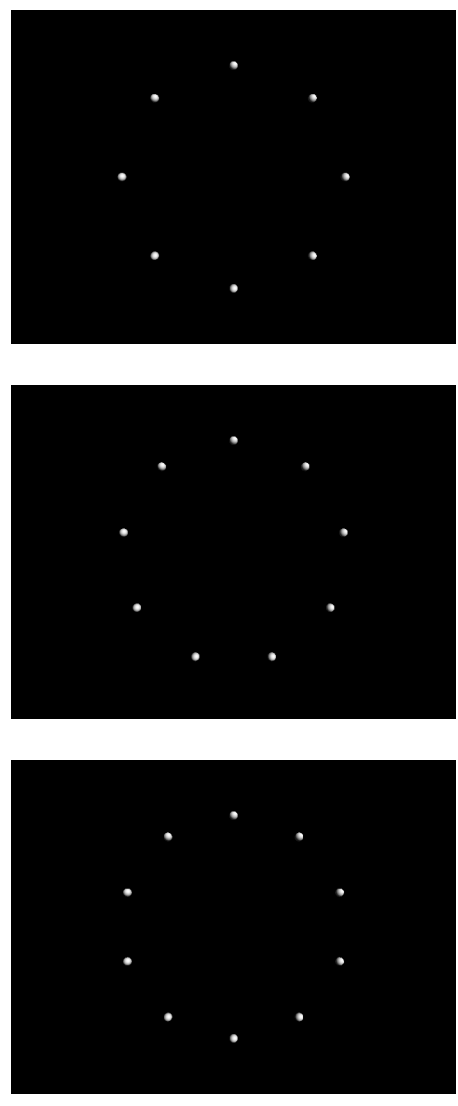

8.45

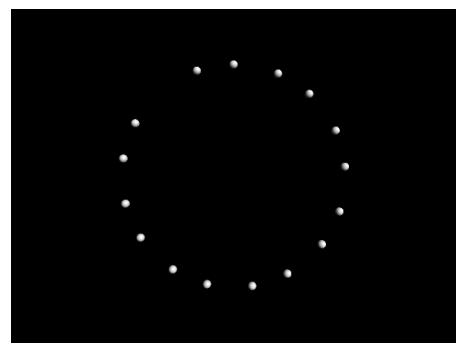

Differential dynamics example-spheres moving

Musical correspondence in a rose curve pattern

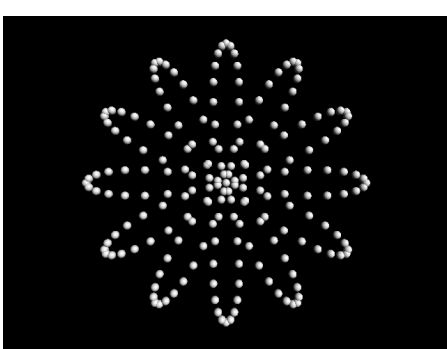

pitches are approximate
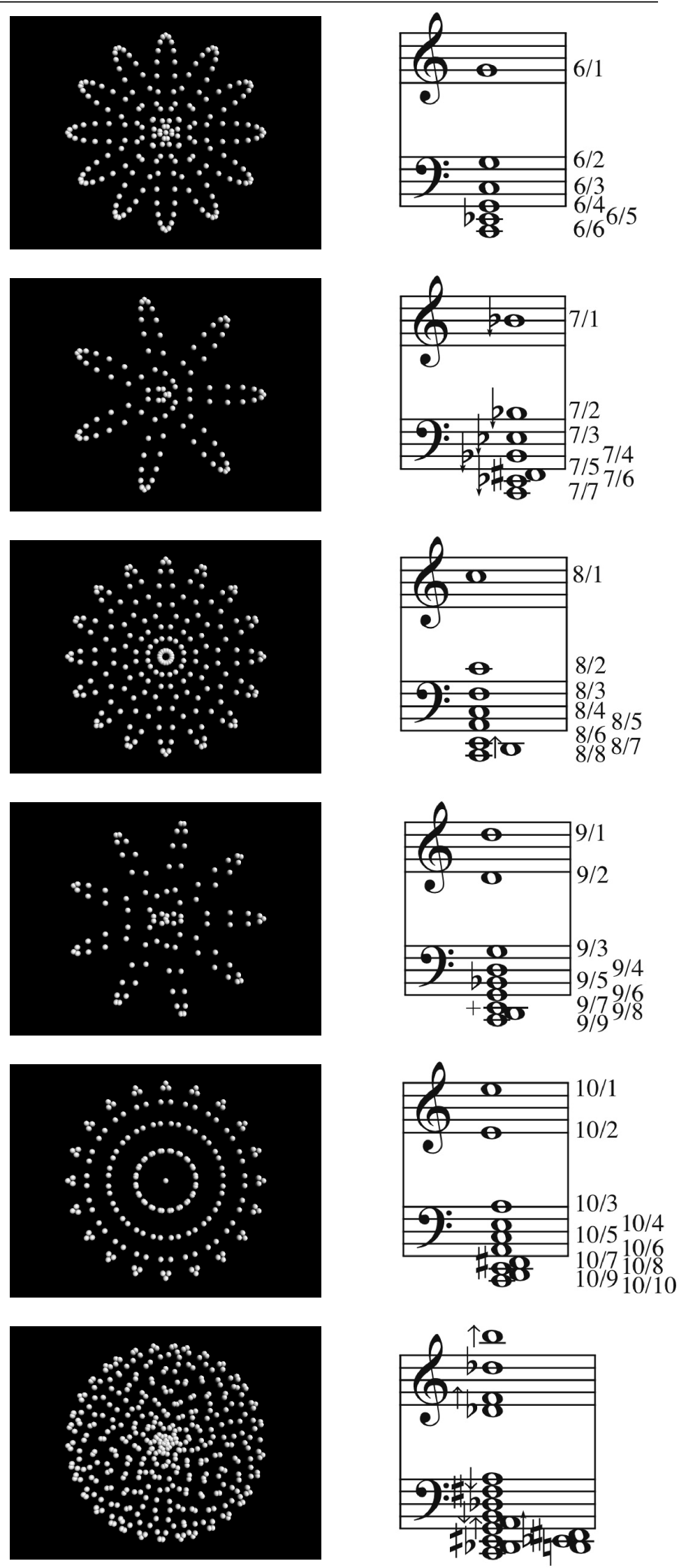

Computer Music Journal 
Figure 3. Still from

Hiway 70.

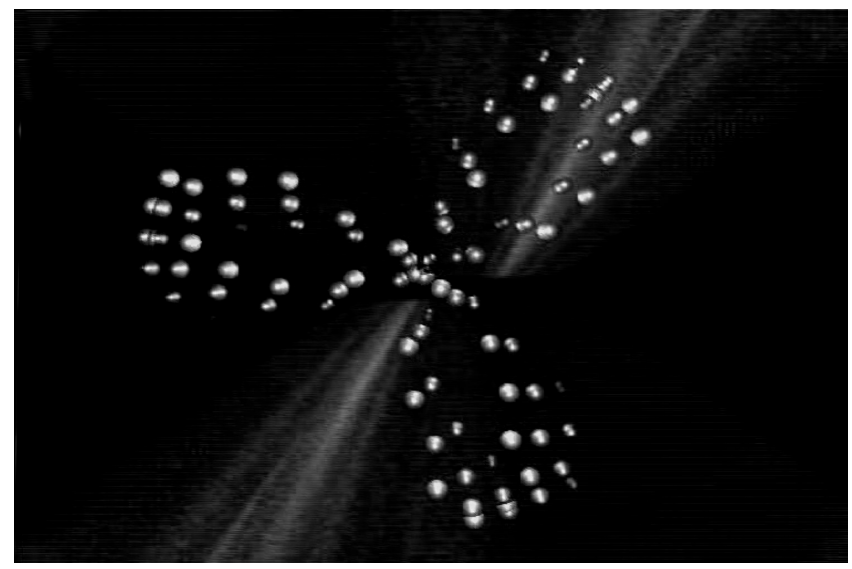

consonance. I created the music entirely in Just intonation, using harmonies which were often direct analogues of the patterns of visual symmetry (see Figures 3 and 4).

Just as digital technology allowed me to control the visual elements with precision necessary for differential dynamics, so did Csound realization of the music allow me to create a Just intonation system which could freely modulate between tonal centers. (The Csound code for Hiway 70 is on the CD-ROM accompanying Boulanger 2000. See also Alves 2000 in the same volume.) I mostly used POV-ray to realize the images. Csound and POV-ray are comparable in that they are languages freely available for a variety of platforms that allow the power and specificity to implement my vision of differential dynamics and dynamic Just intonation, among many other advantages, of course.

Static Cling (2000) explores the ways in which harmonic patterns can emerge from visual or auditory chaos. The video begins with television static accompanied by multiple tracks of overlapping chatter of news anchors resynthesized through linear prediction and then driven with noise. Gradually the noisy chatter is resonated into specific harmonic frequencies emphasizing prime relationships of 7 and 11 while the random fluctuations of the video static align themselves into particular shapes and grids.

The principles of differential motion can also be reflected the rhythmic dimension of the music. In Static Cling sets of vertical lines flash in correspon-
Figure 4. Still from

Hiway 70.

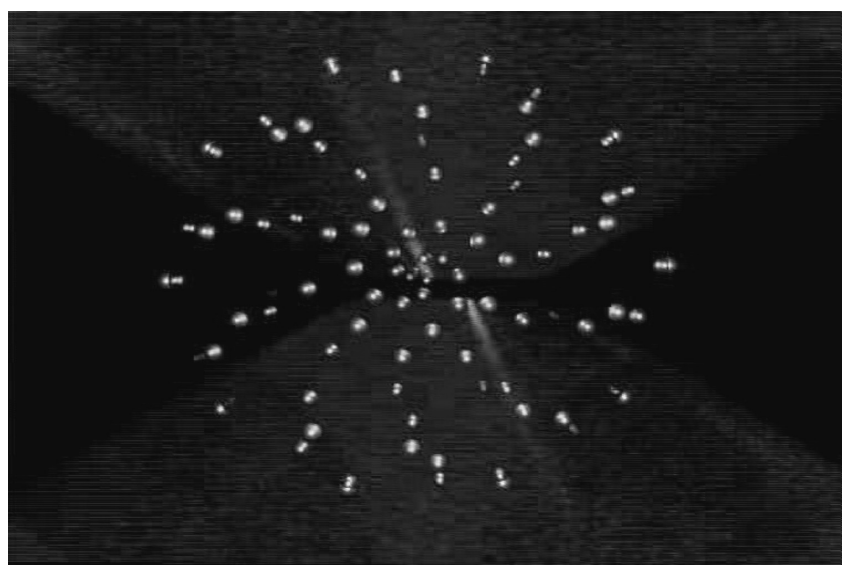

dence to several layers of repetitive polyrhythmic patterns. Each set of lines moves in harmonic proportion with the others, so that they line up at metrically important points. The lines and other shapes which follow in this work move in a wider variety of curve types than in previous works, but the principle is the same. The elements line up into symmetrical patterns at points of stability in the composition, reflecting the simultaneously consonant Just ratios in the music (see Figures 5 and 6).

\section{aleph}

In my next work, aleph (2002), I explored the ways in which Whitney's principles of patterned motion creating and resolving expectation could be extrapolated to approaches sometimes not involving differential dynamics at all. I was inspired by ancient Islamic arts of geometric abstraction that find their high point in the intricate tessellations of the Alhambra in Spain or the Isfahan mosque in Iran, exquisite frozen examples of Whitney's points of visual resonance. In aleph, I "unfroze" those elaborate patterns so that they could reform into new ones at points of tonal stability in the accompanying music.

The great philosophical schools of medieval Baghdad and elsewhere in the Islamic world deeply felt the influence of Pythagoreanism and Platonism, attesting to the power of number in music, art, calligraphy, and religious symbolism. Critchlow (1976) 
Figure 5. Still from Static Cling.

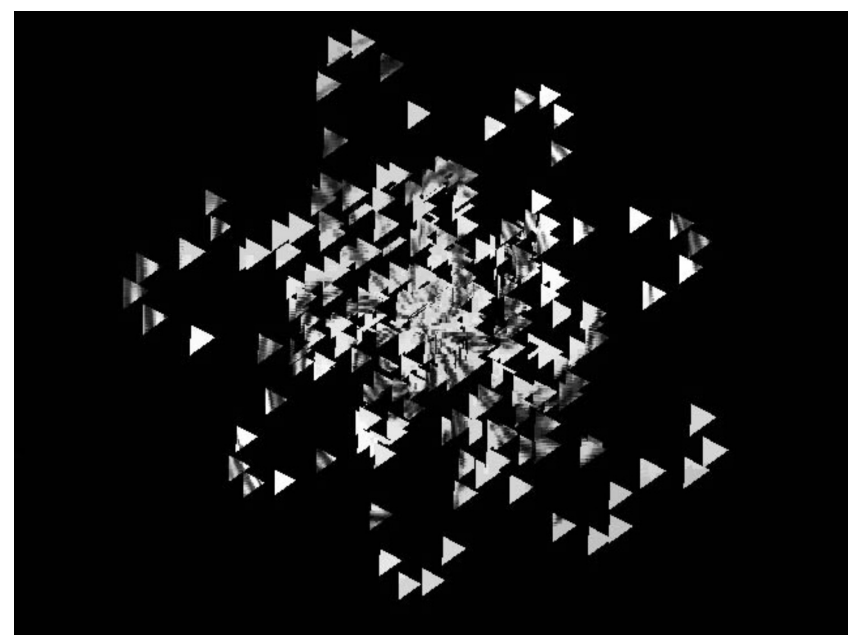

showed how Islamic art is built up through patterns of number, starting with the monad, unity, which symbolically recapitulates creation when it is extended into two dimensions into the circle, the tessellating polygons of the triangle, square, and hexagon, and finally more ornate manifestations. He relates this extension of unity to the first letter of the Arabic alphabet, aleph, as the "creative ray which initiates existence at the diacritical point of bey [the second character] and thence proceeds to expand horizontally with the lateral gesture of the second character. By this the fundamental three-fold nature of reality is established-the descent of the light, the expansion into creation and (in the symbolism of the written words of the Quran) the means whereby the 'light' returns to its source" (p. 8).

Rather than relying on harmonics or subharmonics to form the basis for the Just intonation, I instead turned to structures known as "hexanies" to establish points of musical repose and stasis in the soundtrack. Hexanies, a type of "combination product set" invented by the visionary tuning theorist Ervin Wilson, are sets of six pitches created through the various possible pairings of four selected integer factors (Wilson 1989; Grady 1991). A characteristic of combination product sets that distinguishes them from traditional approaches to Just intonation is that no one pitch in the set necessarily has priority over the others. Like ever-expanding tessellation patterns that offer multiple perspectives of what
Figure 6. Still from Static

Cling.

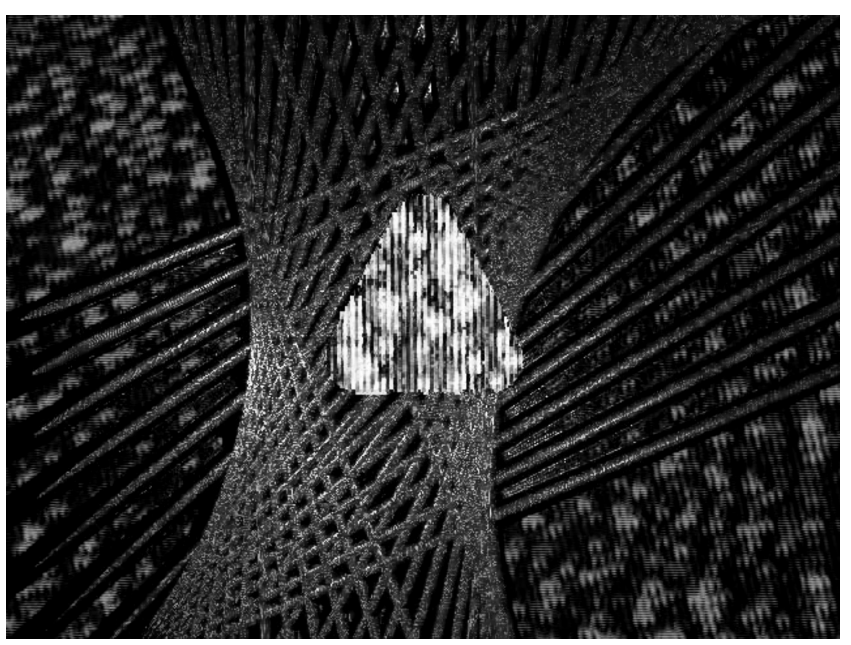

functions as a center, this approach allows pitch sets to retain the integrity of Just harmonic structure together with the ability to float free.

In the beginning of aleph, a formlessness gradually coalesces into visual and musical patterns. Resonant drones are eventually replaced with bell-like tones that follow the mathematical patterns of change-ringing. In this English folk art, groups of bell ringers follow strict permutations of the order of a set of bells, so that each ringer follows a "path" through the successive orders that I envision rather like the paths that the eye may traverse in following the interlocking weaves of Islamic design. In my version other attributes such as octave, density, and pitch sets gradually shift together with the changes of bells. The frequencies of the bell partials are tuned to the same pitches in the hexany then in use, so that the timbres will retain a consonant relationship in the context of the pitch sets (Sethares 1999).

By the time the visual patterns coalesce into striking symmetries, so too do the pitch sets arrive at stable hexanies (see Figures 7 and 8). In between pitches change gradually from one set to the next, reflecting the visual disorder as one pattern slowly transforms into the next. Again, the flexibility of the Csound language enabled me to freely shift between pitch sets without having to establish a single fixed gamut of pitches. (This approach contrasts with that of some other composers who prefer to explore the structure of a single combination 


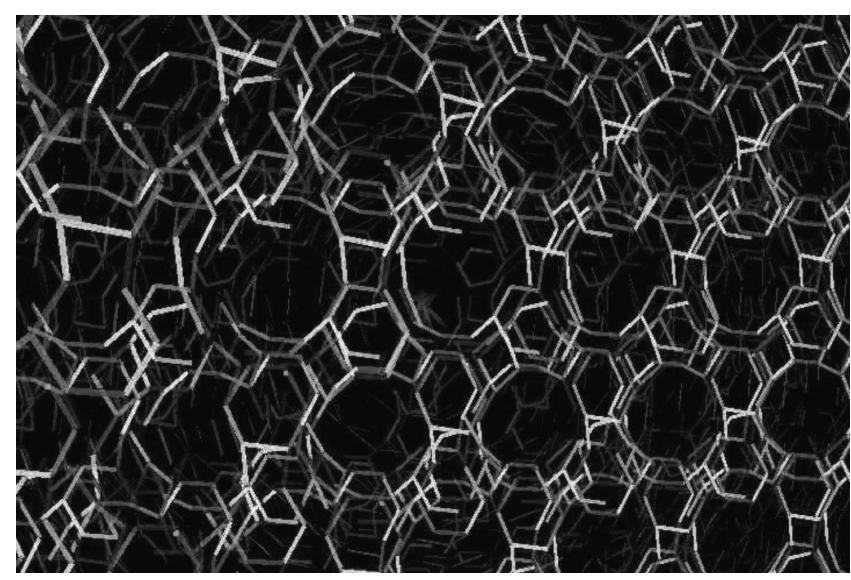

Figure 7

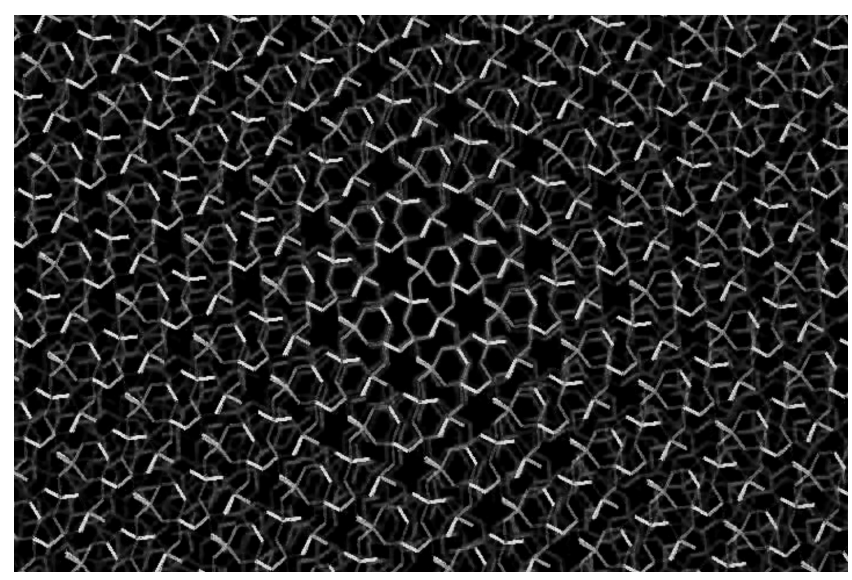

Figure 8

product set within a particular composition. Among the composers who have explored combination product sets in their works are Warren Burt, Kraig Grady, Greg Schiemer, and Stephen James Taylor.)

\section{Future Harmony}

John Whitney recognized that his work represented the infancy of an art form, but suggested that, "Composers will discover a congruence of auralvisual partnership as productive as that which they found for centuries in writing for combinations of all kinds. .. . That partnership will be grounded on valid harmonic interrelationships equally applicable to sound and image" (Whitney 1980, p. 18). Even as he predicted the digital computer and video technology would launch a new golden age of artistic possibilities, he remained convinced that the success of a new art of visual motion would depend on its basis in fundamental principles extending from the canon of Pythagoras to the artful play of tension and resolution in European musical harmonies.

This article illustrates some new possibilities that creatively apply Whitney's ideas as a foundation to achieve a complementarity of music and visual art in motion. Within the psychologically powerful but indefinitely flexible applications of these general principles lie boundless opportunities for new visions of a fluid architecture of form, motion, and music.

\section{References}

Alves, Bill. 2000. "Using Alternate Tunings in Csound." In CD-ROM accompanying Boulanger, Richard, ed. The Csound Book. Cambridge, Massachusetts: MIT University Press.

Boulanger, Richard, ed. 2000. The Csound Book. Cambridge, Massachusetts: MIT University Press.

Collopy, Fred. 2000. "Color, Form, and Motion: Dimensions of a Musical Art of Light." Leonardo 33(5): 355-360.

Cornford, Francis Macdonald. 1937. Plato's Cosmology. London: K. Paul, Trench, Trubner \& Co.

Critchlow, Keith. 1976. Islamic Patterns: An Analytical and Cosmological Approach. London: Thames \& Hudson.

Franklin, John Curtis. 2002. "Harmony in Greek and Indo-Iranian Cosmology." The Journal of IndoEuropean Studies 30(1/2):1-25.

Grady, Kraig. 1991. "Ervin Wilson's Hexanies." 1/1: Journal of the Just Intonation Network 7(1):8-15.

Jones, Tom Douglas. 1972. The Art of Light and Color. New York: Van Nostrand Reinhold.

Klein, Adrian Bernard. 1937. Coloured Light: An Art Medium. London: The Technical Press.

Monro, G., and J. Pressing. 1998. "Sound Visualization Using Embedding: The Art and Science of Auditory Autocorrelation." Computer Music Journal 22(2): 20-34. 
Moritz, William. 2004. Optical Poetry: The Life and Work of Oskar Fischinger. Bloomington: Indiana University Press.

Partch, Harry. 1974. Genesis of a Music. 2nd ed. New York: Da Capo.

Pellegrino, Ronald. 1983. The Electronic Arts of Light and Sound. New York: Van Nostrand Reinhold.

Sethares, William A. 1999. Tuning, Timbre, Spectrum, Scale. London: Springer Verlag.

Tenney, James. 1988. A History of Consonance and Dissonance. New York: Excelsior.
Whitney, John. 1980. Digital Harmony: On the Complementarity of Music and Visual Art. New York: Byte Books.

Whitney, John. 1984. "To Paint on Water: The Audiovisual Duet of Complementarity." Computer Music Journal 18(3):44-52.

Wilson, Ervin. 1989. "D'Alessandro, Like a Hurricane." Xenharmonikon XII:1-39. 